\section{FROM THE EDITOR...}

Three papers are featured in Volume 27 of the JFDE. The first paper, "Visual Feedback on the Static and Kinematic Characteristics of Handwriting," is authored by Michael Pertsinakis who completed his $\mathrm{PhD}$ in Forensic Science from Staffordshire University in the UK in 2017. He presented the paper at the 2017 International Graphonomics Society's (IGS) Biennial conference in Gaeta, Italy and expanded the paper for the JFDE. Dr. Pertsinakis is a Senior Examiner of Questioned Documents at the Chartoularios P.C. Laboratory of Questioned Document Studies in Greece.

The second paper, "Alzheimer's Disease and Signature Execution," received the Association of Forensic Document Examiner's award for the best student paper at the 2017 IGS conference. The lead author Carina Fernandes received her Master's degree in Forensic Medicine in 2010 from the University of Porto (Portugal). Her thesis was titled, "Influence of Alzheimer's Disease on Handwriting." She has presented on the subject at the 2015 and 2016 conferences of the European Network of Forensic Handwriting Experts in Germany and Switzerland. Ms. Fernandes is currently working towards her doctorate in forensic sciences. Her co-author José Manuel Lopes Lima received his medical degree from the Faculty of Medicine at the University of Porto (Portugal) in 1972. Since 2007, Dr. Lima has been the Head of the Neurology Service at Santo Antonio General Hospital in Portugal.

The third author, Roger Stritmatter, $\mathrm{PhD}$, is a guest author and a professor in the Department of Humanities at Coppin State University in Baltimore, Maryland. His paper is titled, "Arrangement, Natural Variation, Legibility, and Line Quality as Discriminating Elements in Forensic Handwriting Analysis: A Study of Herman Melville's April 11, 1846 'Hydrarchos' Satire." He said that he has long been interested in the writings of Herman Melville after writing a paper in high school on Melville's classic Moby Dick. In 2009, he purchased the Hydrarchos"after doing extensive research on Melville. He had a hunch that Melville had written this satirical newspaper. To test out his hunch, he approached Professor Sargur Srihari, head of the CEDAR-FOX PROJECT at the University of Buffalo, to see if he could use his scientific methodology to shed light on the writership of the Hydrarchos. Srihari and his colleagues took up the project and presented two papers on their work (2010 and 2013) that confirmed that Melville was the most likely author. Dr. Stritmatter has agreed to send these papers to anyone who would like to review them - (rstritmatter@coppin.edu). Dr. Stritmatter then decided to approach the question whether Melville had written the Hydrarchos using more traditional methods used by forensic documents examiners based on Huber and Headrick's Discriminating Elements described in their 1999 book, Handwriting Identification: Facts and Fundamentals.

At the request of the Editor, the members the document laboratory of the New Zealand Police Department reviewed the newly released Second Edition of the book, Handwriting Identification: Fact and Fundamentals. Originally authored by Roy A. Huber and A.M. Headrick in 1999, the book was recently updated by Heidi H. Harralson and Larry S. Miller. The document examiners at the New Zealand Document Laboratory agreed to review the book in their individual capacities, and the review does not necessarily reflect the view of the New Zealand Police. Gordon Sharfe, the laboratory's director, has been a long time member of the JFDE's Editorial Board, and we appreciate the assistance that he and his staff have provided over the years.

\section{Update on the Modular Forensic Handwriting method}

Editorial Board member Carolyne Bird (Australia) provides an update to "The Modular Forensic Handwriting Method," published in Volume 26 in 2016. She states that the Modular Forensic Handwriting Method, "is the method of the Australian and New Zealand laboratories represent on the Documents Examination Special Advisory Group (DocSAG). As this is an active document, the editors of the Method have a 2-yearly cycle for review and update of all aspects of the document. Readers of the Journal interested in the Modular Method should note that plans for the next update are underway, and for those who currently apply the Modular Method or are seeking to apply the Method in their practice, the next update will include further changes to the 
conclusion wording. At the time of publication, the DocSAG had agreed to the terminology outlined in Module 10 of the 2016 Version, but had not yet implemented the evaluative reporting approach. As DocSAG laboratories are transitioning to reporting in this manner, the DocSAG has agreed that some aspects of the terminology need to change. This issue will be addressed, along with other updates including expanding the discussion on contextual information, in 2018. Following the release of the amended version, a paper outlining the updated conclusion wording will be submitted to this journal for consideration to publish. In the meantime if you would like to be kept informed of the current position of the DocSAG, please contact corresponding editor for the Modular Method, Carolyne Bird, at carolyne.bird@sa.gov.au.

\section{Acknowledgments and correction}

Carolyne. Bird. Michael Caligiuri, and Joseph Barabe were among the reviewers that provided valuable assistance for this volume. Approximately fifty percent of the papers received by the JFDE are accepted for publication.

The Editor needs to make a correction to "From the Editor" in Volume 25. The Editor stated that the author Tonya Trubshoe held a PhD. The title $P h D$ should have been Master's Degree.

We welcome Michael Pertsinakis (Greece) as a new member of the Editorial Board.

M. Patricia Fisher

Editor 